\title{
Eksperimen dan Simulasi Rangkaian Band Pass Filter (BPF) dengan Resistor dan Kapasitor
}

\author{
Fadliondi ${ }^{1}$, Asriyadi ${ }^{2}$ \\ ${ }^{1}$ Teknik Elektro Univeritas Muhammadiyah Jakarta, ${ }^{2}$ Politeknik Negeri Sriwijaya \\ fadliondi@ftumj.ac.id, asriyadi@polsri.ac.id
}

\section{Abstrak}

Eksperimen dan simulasi terhadap rangkaian band pass filter telah dilakukan. Hasilnya menunjukkan bahwa pada rangkaian band pass filter yang telah disimulasikan dan dirangcang,ketika frekuensinya dinaikkan sampai $1 \mathrm{kHz}$, amplutidonya juga ikut naik, setelah itu, setelah frekuensinya iturunkan sampai $1 \mathrm{MHz}$, amplitudonya kembali turun.

\section{PENDAHULUAN}

Rangkaian band pass filter adalah rangkaian yang mengizinkan lewat sinyal yang memiliki frekuensi pada rentang tertentu dan mengattenuasikan sinyal yang memiliki frekuensi di luar rentang tersebut. Sementara rangkaian low pass filter adalah rangkaian resistor dan kapasitor yang dirangkai secara seri dan yang menjadi outputnya adalah kapasitor [1]. Ada band pass filter Chebyshev klasik yang memakai resonator dari kapasitor aktif yang bisa disetel dan inductor [2]. Dengan perkembangan telepon genggam yang semakin cepat, pemintaan akan bandpass filter dengan performa yang tinggi sangatlah dibutuhkan [3]. Osilator Wien-bridge adalah osilator klasik yang memakai BPF dengan resistor pasif dan kapasitor [4]. Tujuan penelitian kali ini adalah mensimulasikan dan menguji rangkaian bandpass filter secara eksperimen. Saat ini, banyak alat simulasi elektro dan elektronika yang ada di pasaran di mana hasil dari simulasi tersebut dipakai sebagai referensi untuk modifikasi dan verifikasi dari rancangan rangkaian untuk memenuhi persyaratan rangkaian [5].

\section{METODE}

Alat yang dibutuhkan pada eksperimen ini adalah breadboard, 1 buah resistor $10 \mathrm{kohm}, 1$ buah resistor $20 \mathrm{kohm}, 1$ buah kapasitor $1 \mathrm{nF}$ (kode 102), 1 buah kapasitor $100 \mathrm{nF}$ (kode 104), 1 buah function generator, 1 buah osiloskop 2 kanal dan kabel secukupnya. Perangkat lunak yang digunakan untuk simulasi adalah LTSPICE. Gambar 1 menunjukkan rangkaian pada breadboard dan untuk simulasi.

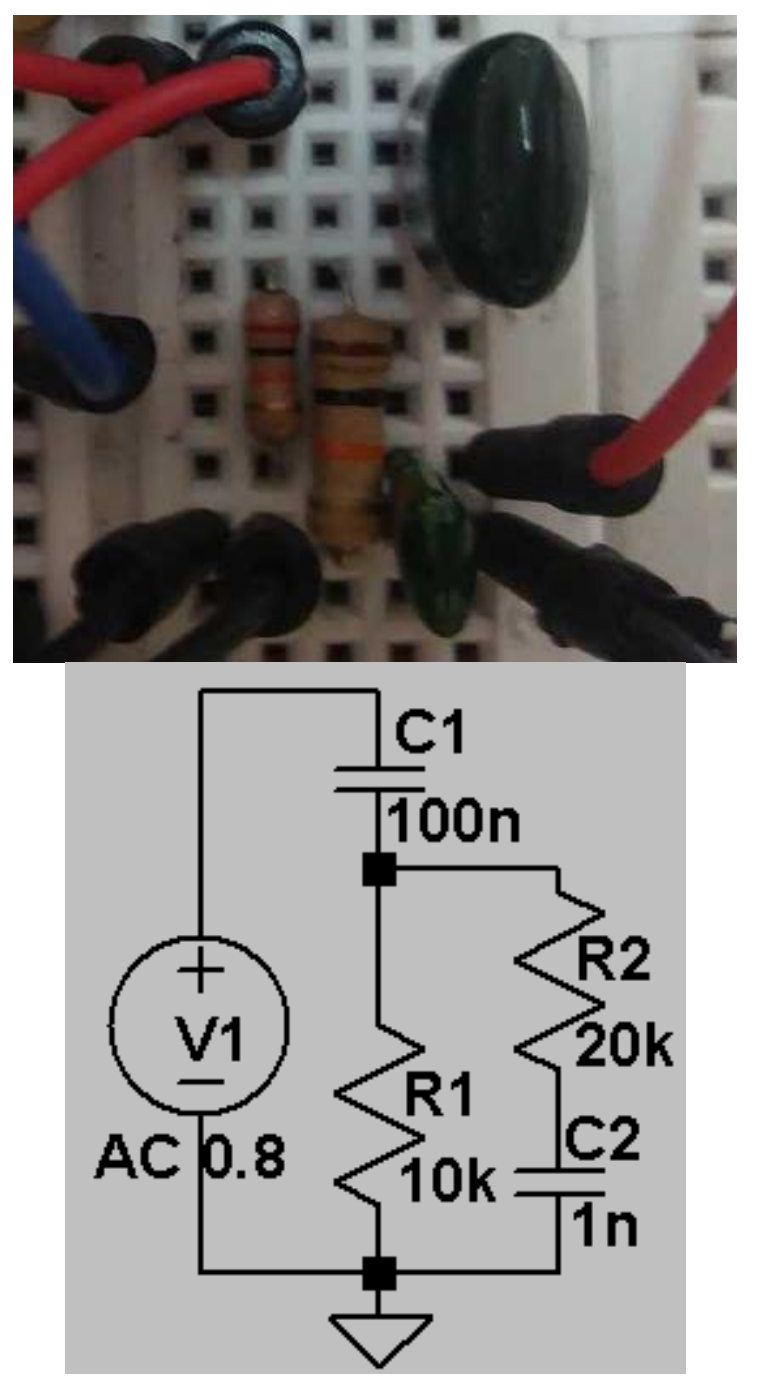

Gambar 1 Rangkaian band pass filter dengan resistor dan kapasitor (kiri : eksperimen, kanan : simulasi).

3 HASIL DAN PEMBAHASAN UNTUK RANGKAIAN BAND PASS FILTER 
RESISTOR (elektRonika kEndali telekomunikaSI tenaga liSTrik kOmputeR) Vol. 1 No. 2 e-ISSN : 2621-9700, p-ISSN : 2654-2684
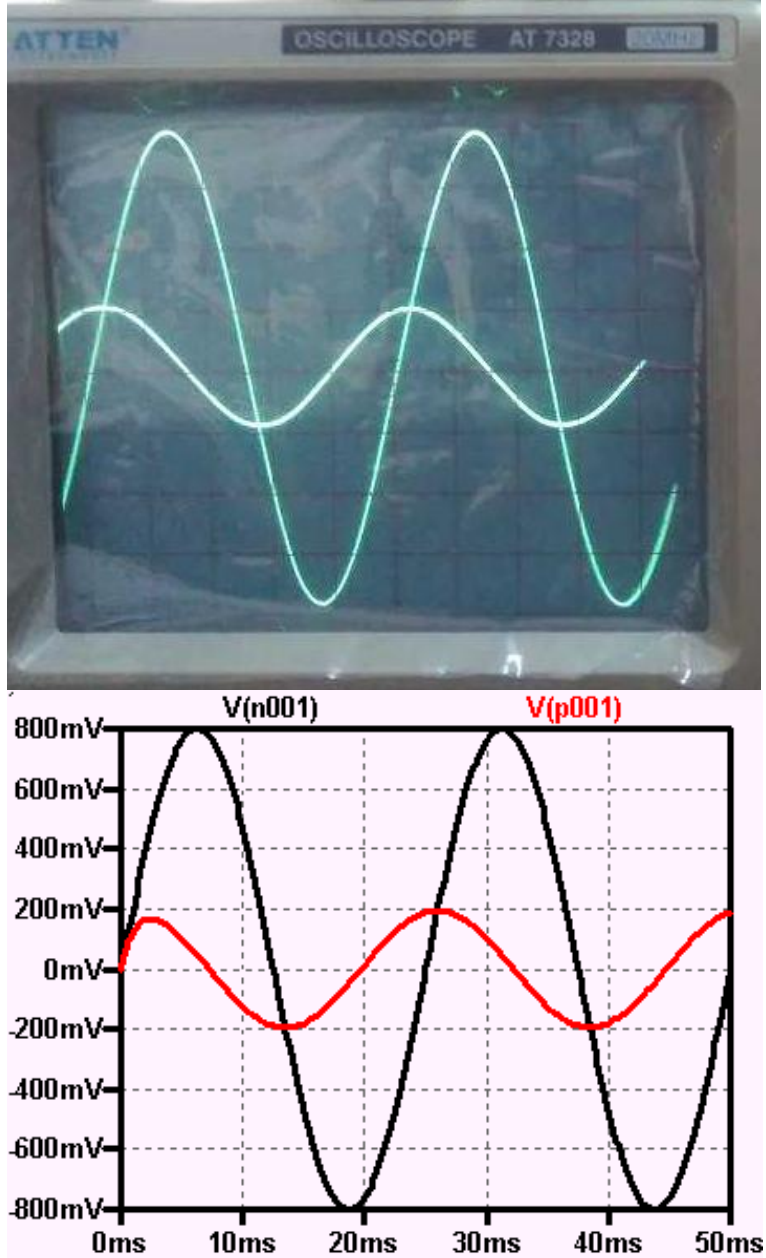

Gambar 2 Hasil eksperimen (kiri) dan simulasi (kanan) rangkaian bpf dengan $\mathrm{f}=40 \mathrm{~Hz}$.

Gambar 2 menunjukkan hasil eksperimen (kiri) dan simulasi (kanan) rangkaian bpf dengan frekuensi $40 \mathrm{~Hz}$. Amplitudo dari sinyal keluarannnya turun hingga seperempat kali dari sinyal masuk. Gambar 3 adalah grafik dari hasil eksperimen dan simulasi rangkaian bpf dengan f rekuensi $100 \mathrm{~Hz}$. Aplitudonya naik menjadi sekitar $300 \mathrm{mV}$ dibandingkan ketika frekuensinya $100 \mathrm{~Hz}$.
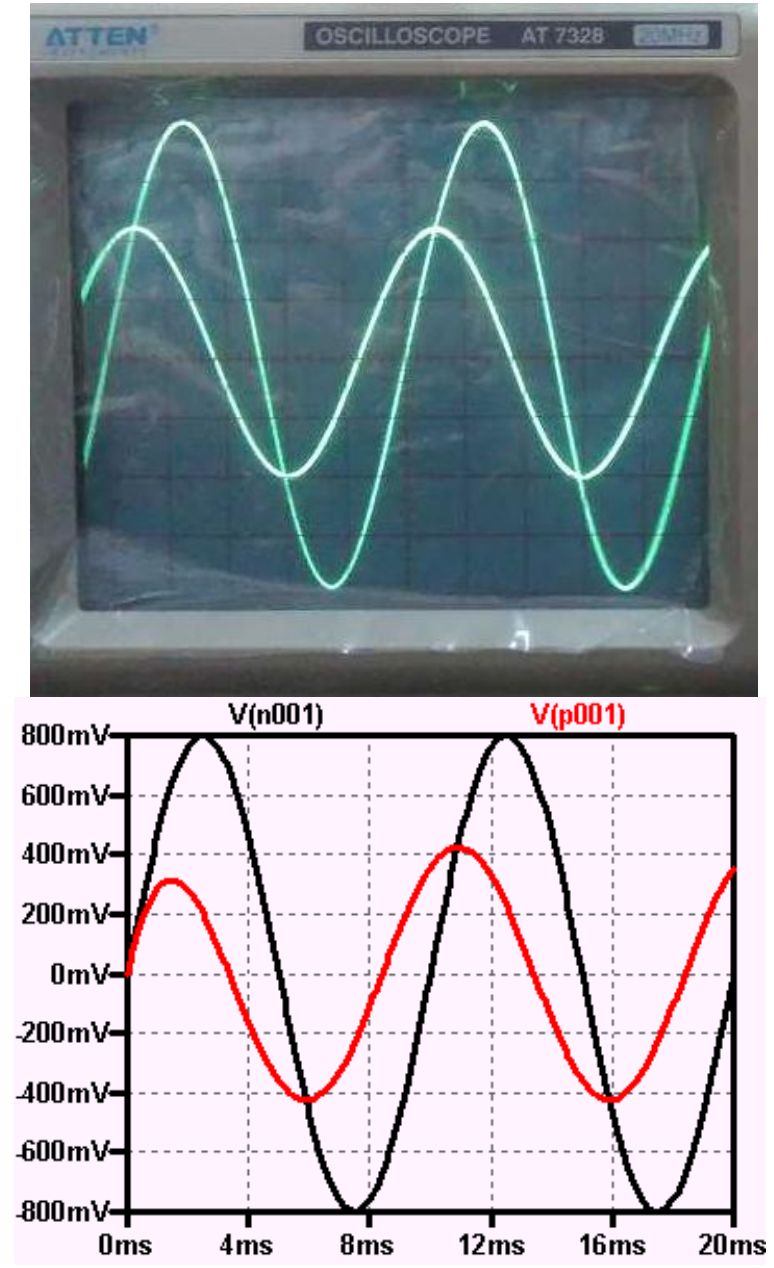

Gambar 3 Hasil eksperimen (kiri) dan simulasi (kanan) rangkaian bpf dengan $\mathrm{f}=100 \mathrm{~Hz}$. 
RESISTOR (elektRonika kEndali telekomunikaSI tenaga liSTrik kOmputeR) Vol. 1 No. 2 e-ISSN : 2621-9700, p-ISSN : 2654-2684
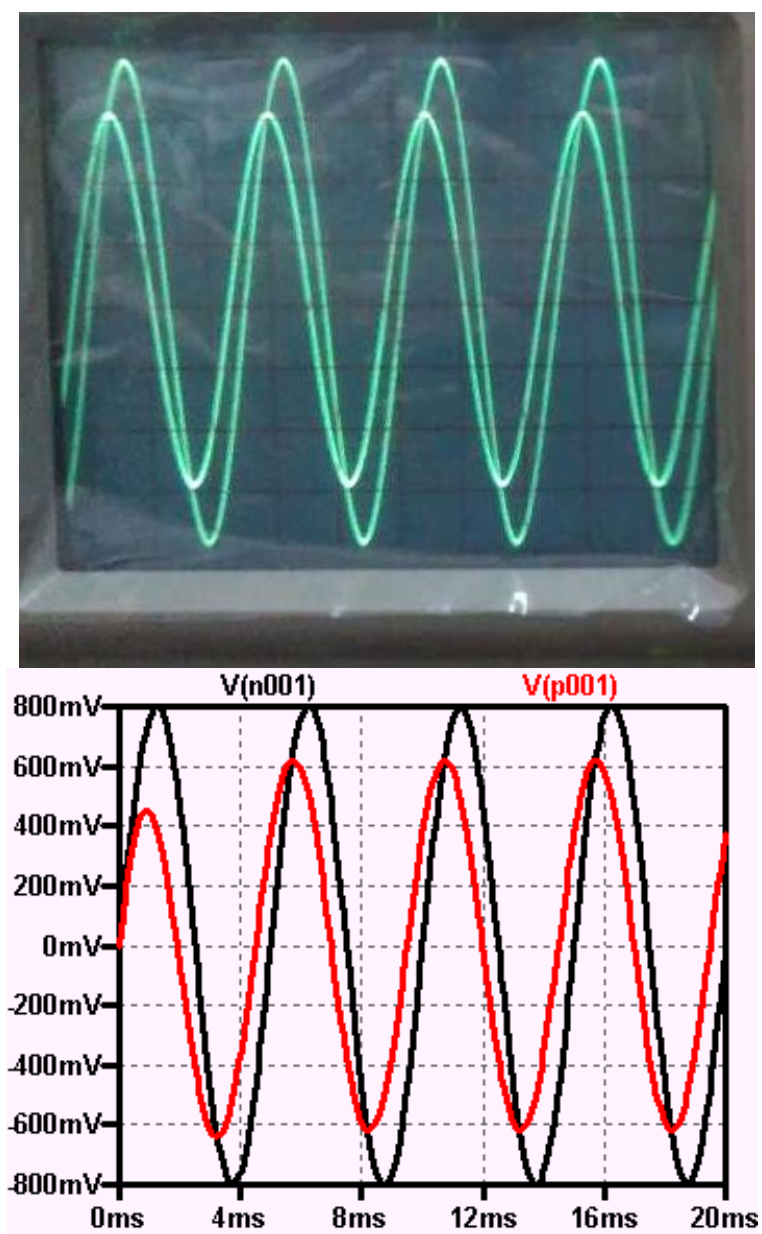

Gambar 4 Hasil eksperimen (kiri) dan simulasi (kanan) rangkaian bpf dengan $\mathrm{f}=200 \mathrm{~Hz}$.

Gambar 4 menunjukkan hasil eksperimen (kiri) dan simulasi (kanan) rangkaian bpf dengan frekuensi $200 \mathrm{~Hz}$ dan Gambar 5 menampilkan hasil eksperimen dan simulasi dari rangkaian bpf dengan frekuensi $400 \mathrm{~Hz}$.
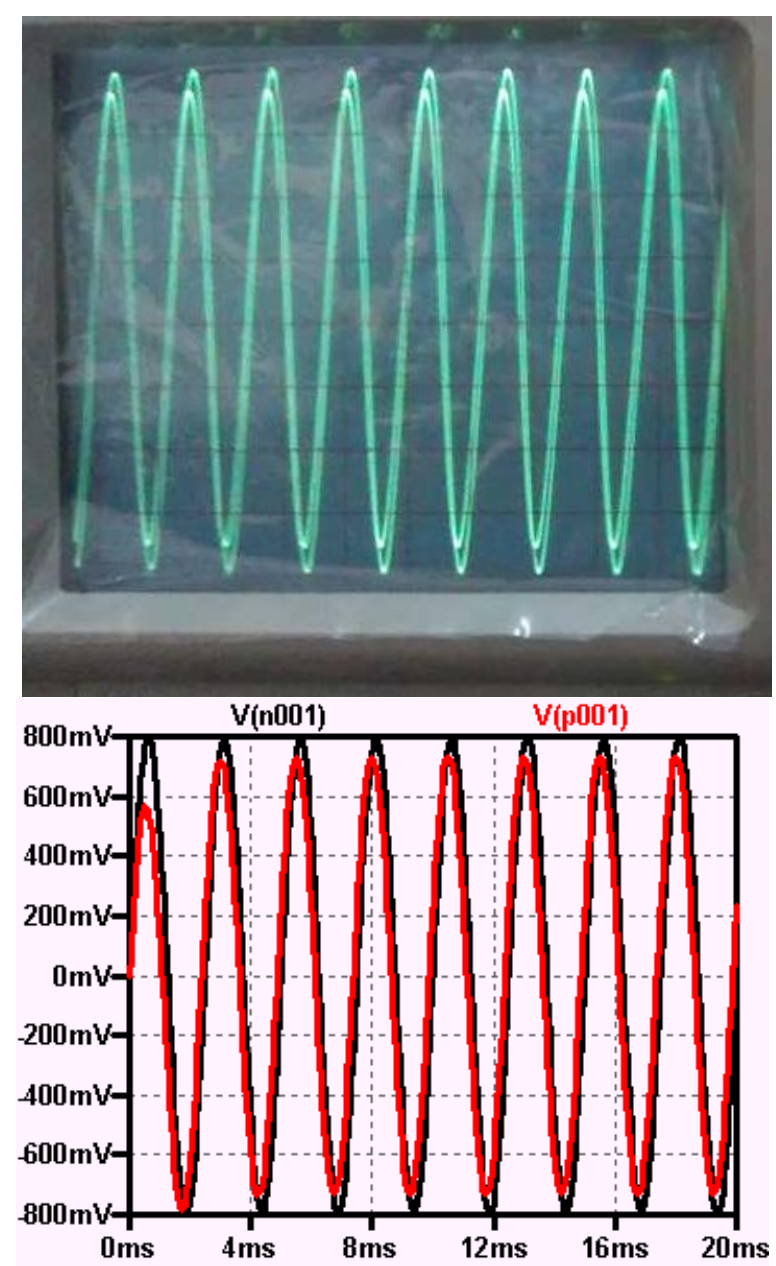

Gambar 5 Hasil eksperimen (kiri) dan simulasi (kanan) rangkaian bpf dengan $\mathrm{f}=400 \mathrm{~Hz}$. 
RESISTOR (elektRonika kEndali telekomunikaSI tenaga liSTrik kOmputeR) Vol. 1 No. 2 e-ISSN : 2621-9700, p-ISSN : 2654-2684

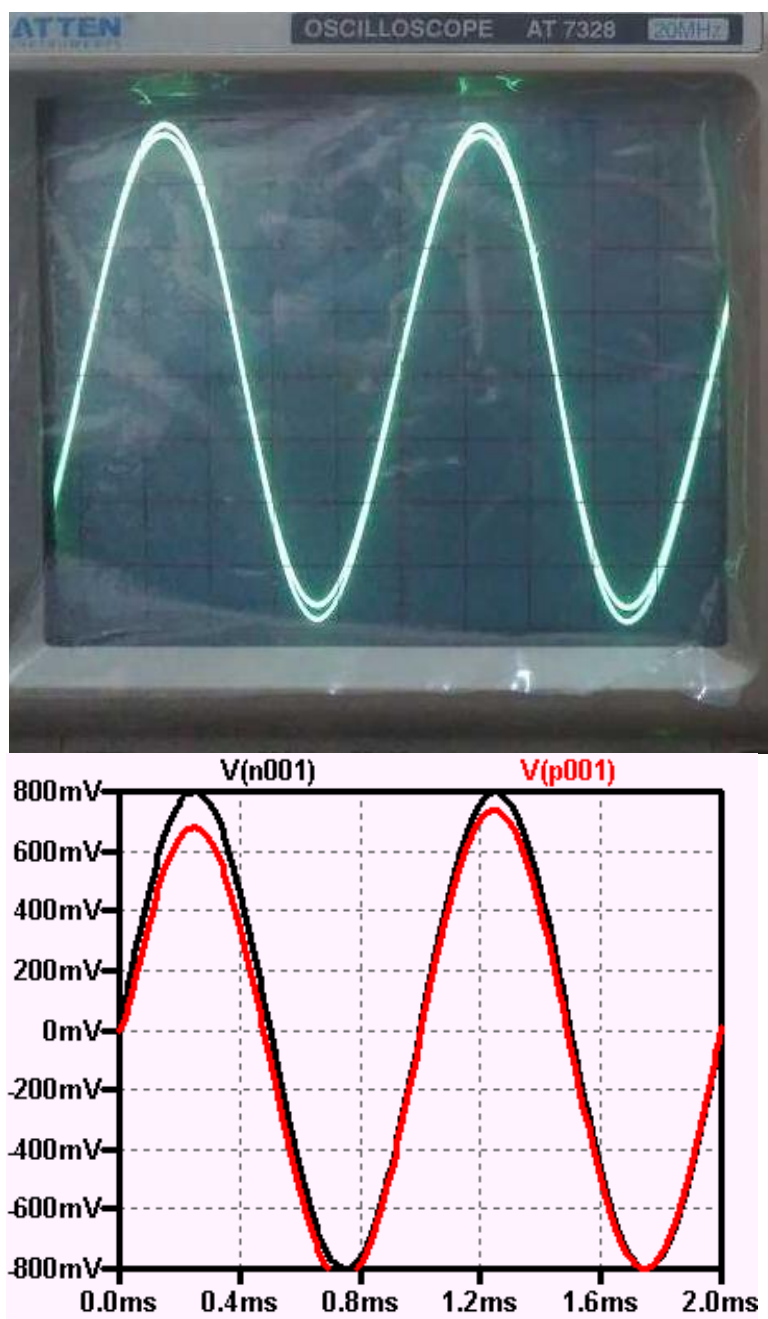

Gambar 6 Hasil eksperimen (kiri) dan simulasi (kanan) rangkaian bpf dengan $\mathrm{f}=1 \mathrm{kHz}$
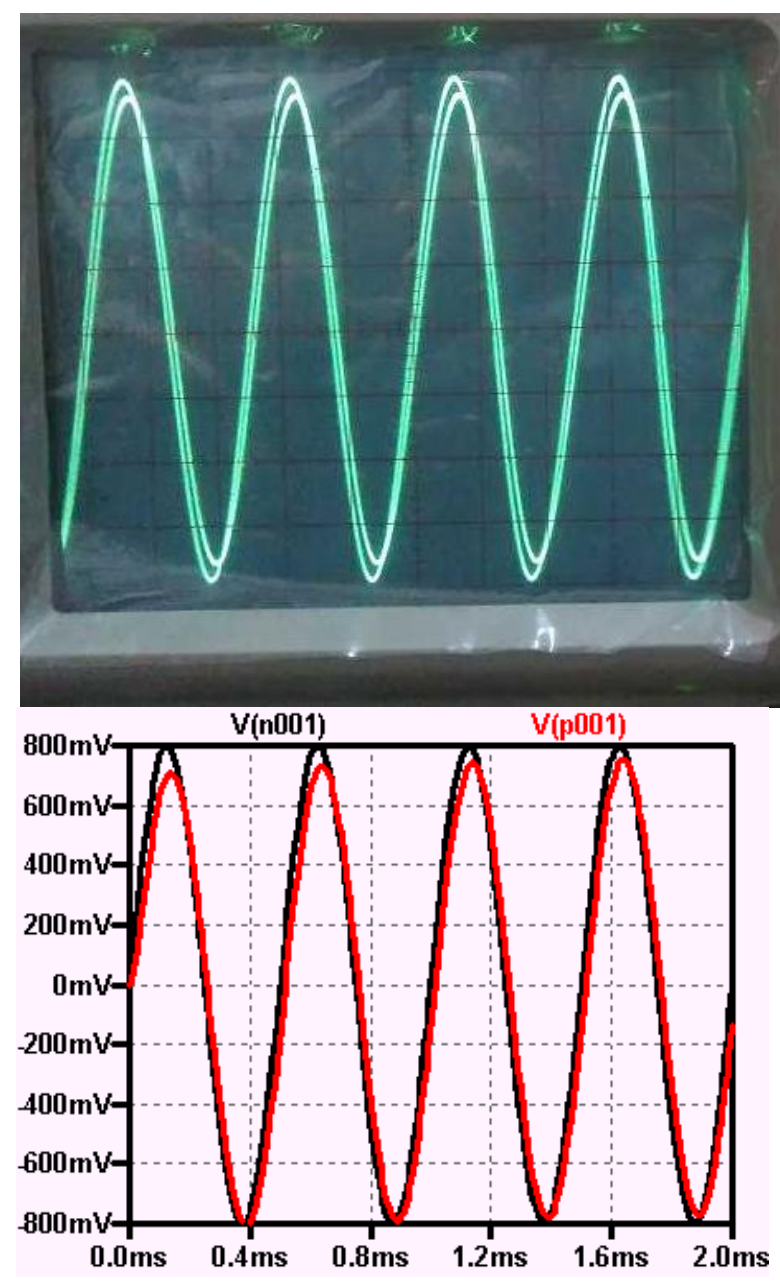

Gambar 7 Hasil eksperimen (kiri) dan simulasi (kanan) rangkaian bpf dengan $\mathrm{f}=2 \mathrm{kHz}$. 
RESISTOR (elektRonika kEndali telekomunikaSI tenaga liSTrik kOmputeR) Vol. 1 No. 2 e-ISSN : 2621-9700, p-ISSN : 2654-2684
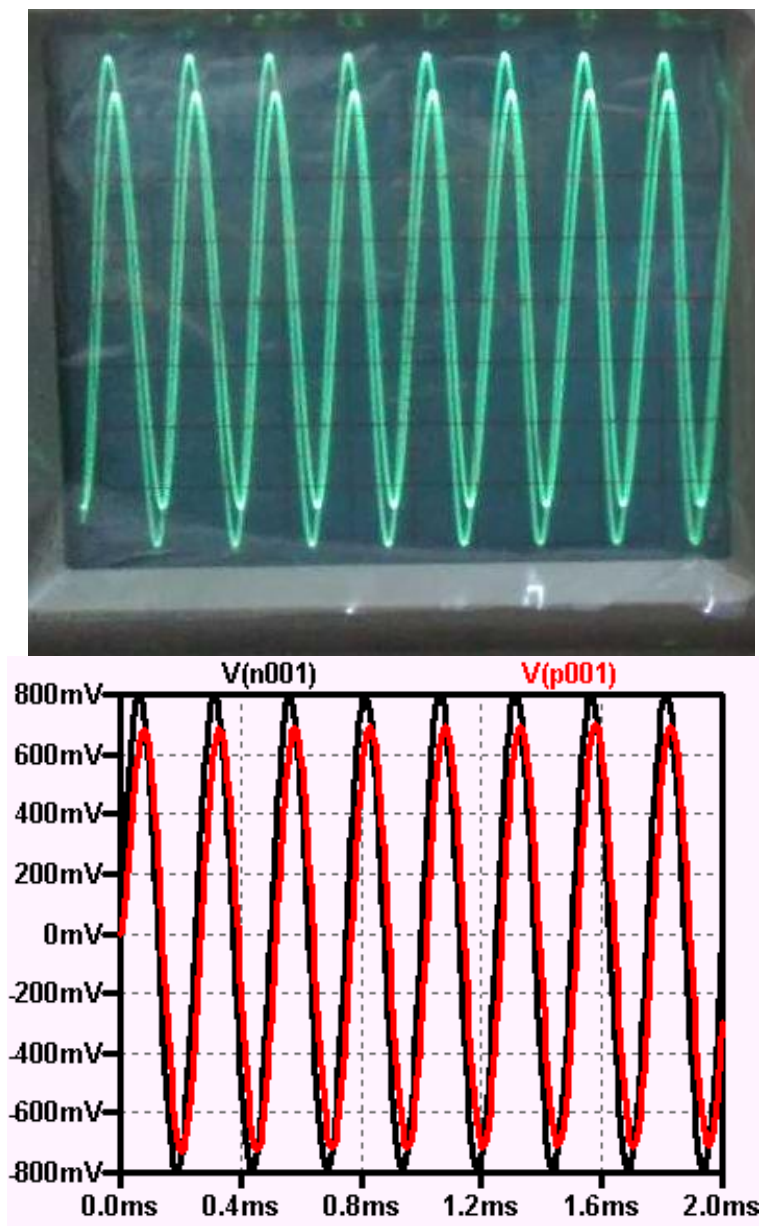

Gambar 8 Hasil eksperimen (kiri) dan simulasi (kanan) rangkaian bpf dengan $\mathrm{f}=4 \mathrm{kHz}$.

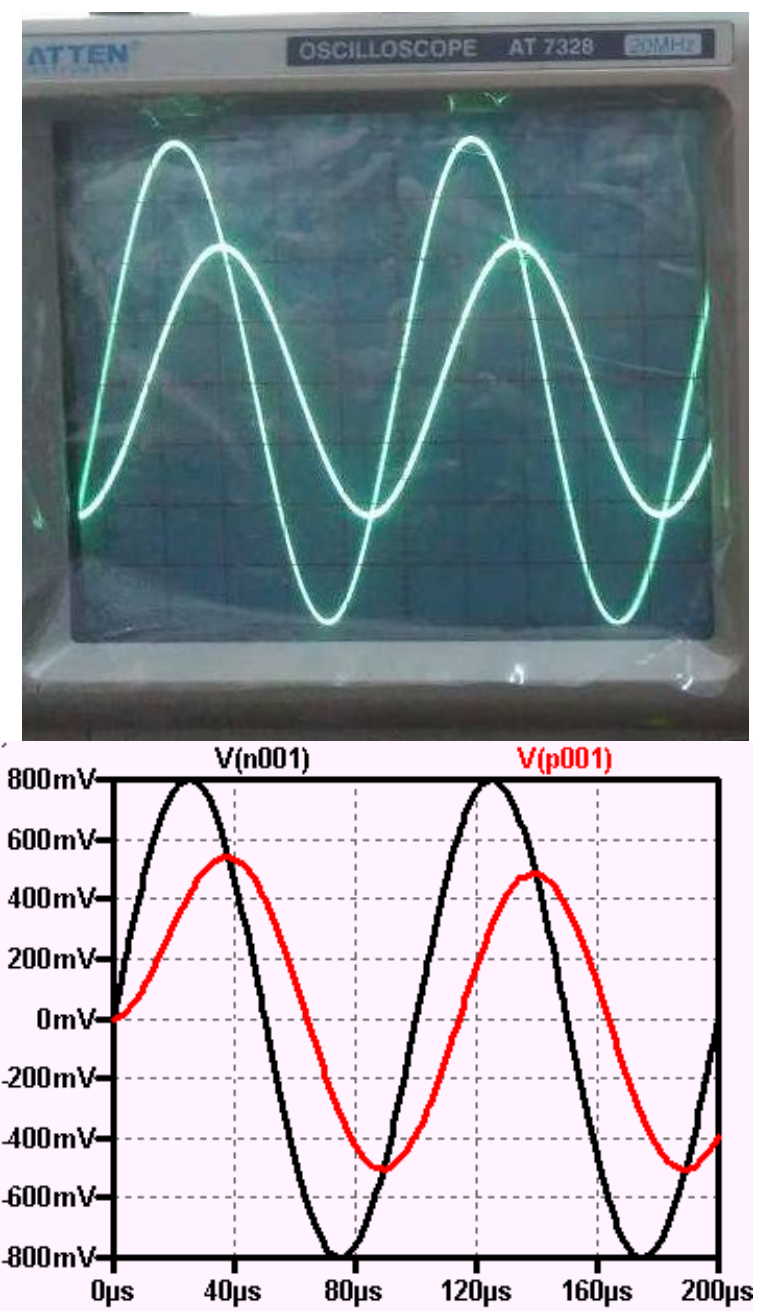

Gambar 9 Hasil eksperimen (kiri) dan simulasi (kanan) rangkaian bpf dengan $\mathrm{f}=10 \mathrm{kHz}$. 
RESISTOR (elektRonika kEndali telekomunikaSI tenaga liSTrik kOmputeR) Vol. 1 No. 2 e-ISSN : 2621-9700, p-ISSN : 2654-2684

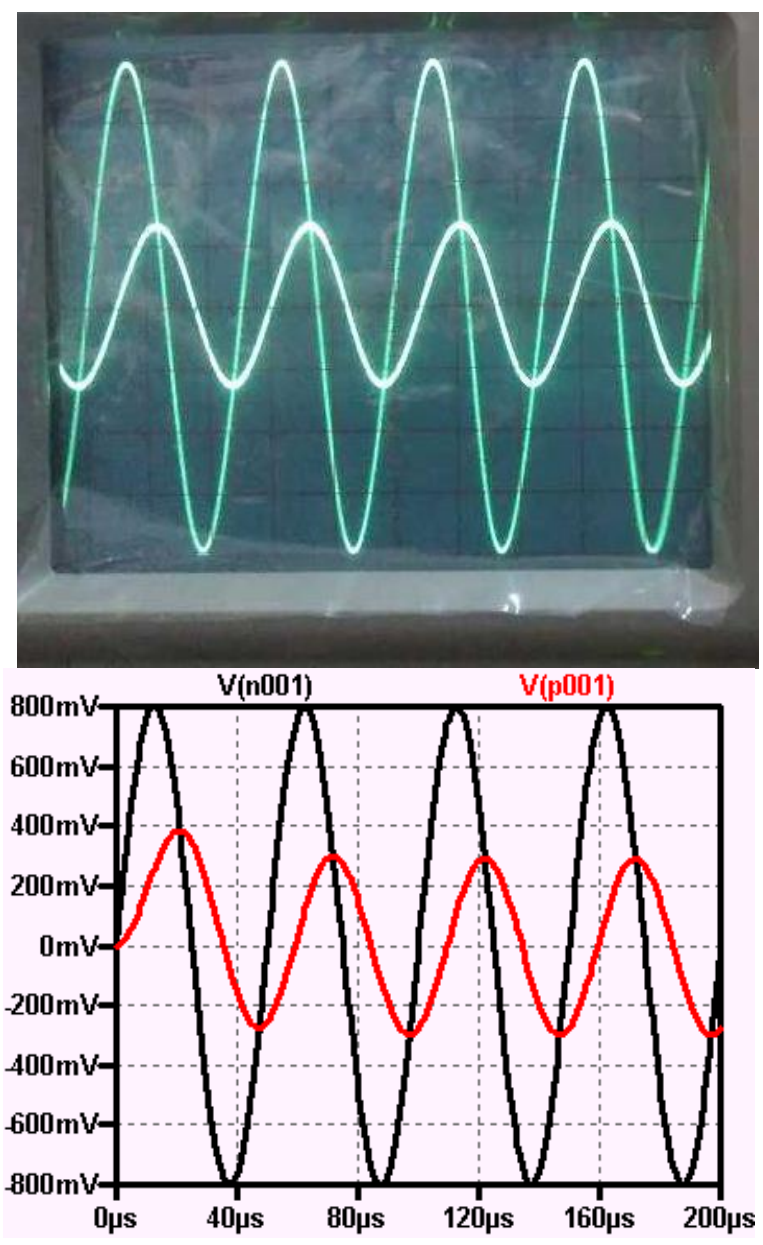

Gambar 10 Hasil eksperimen (kiri) dan simulasi (kanan) rangkaian bpf dengan $\mathrm{f}=20 \mathrm{kHz}$.
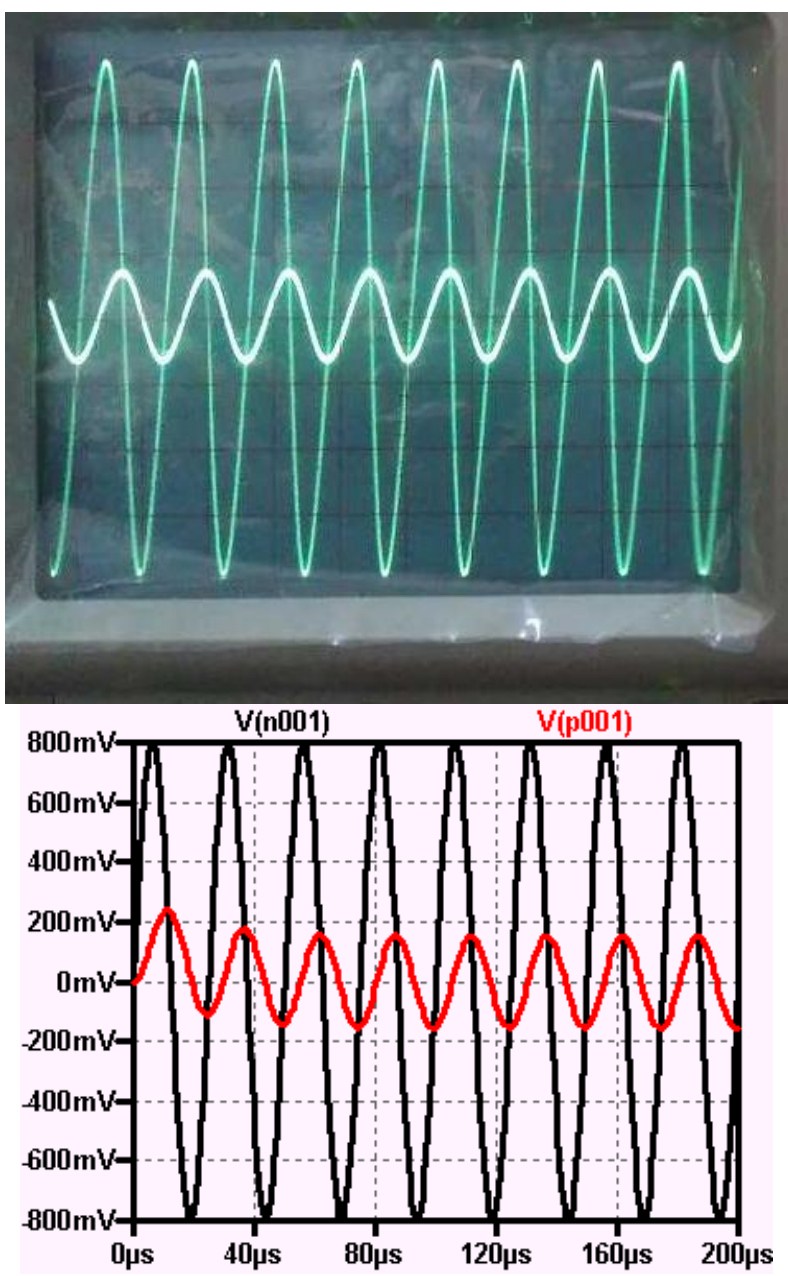

Gambar 11 Hasil eksperimen (kiri) dan simulasi (kanan) rangkaian bpf dengan $\mathrm{f}=40 \mathrm{kHz}$. 
RESISTOR (elektRonika kEndali telekomunikaSI tenaga liSTrik kOmputeR) Vol. 1 No. 2 e-ISSN : 2621-9700, p-ISSN : 2654-2684
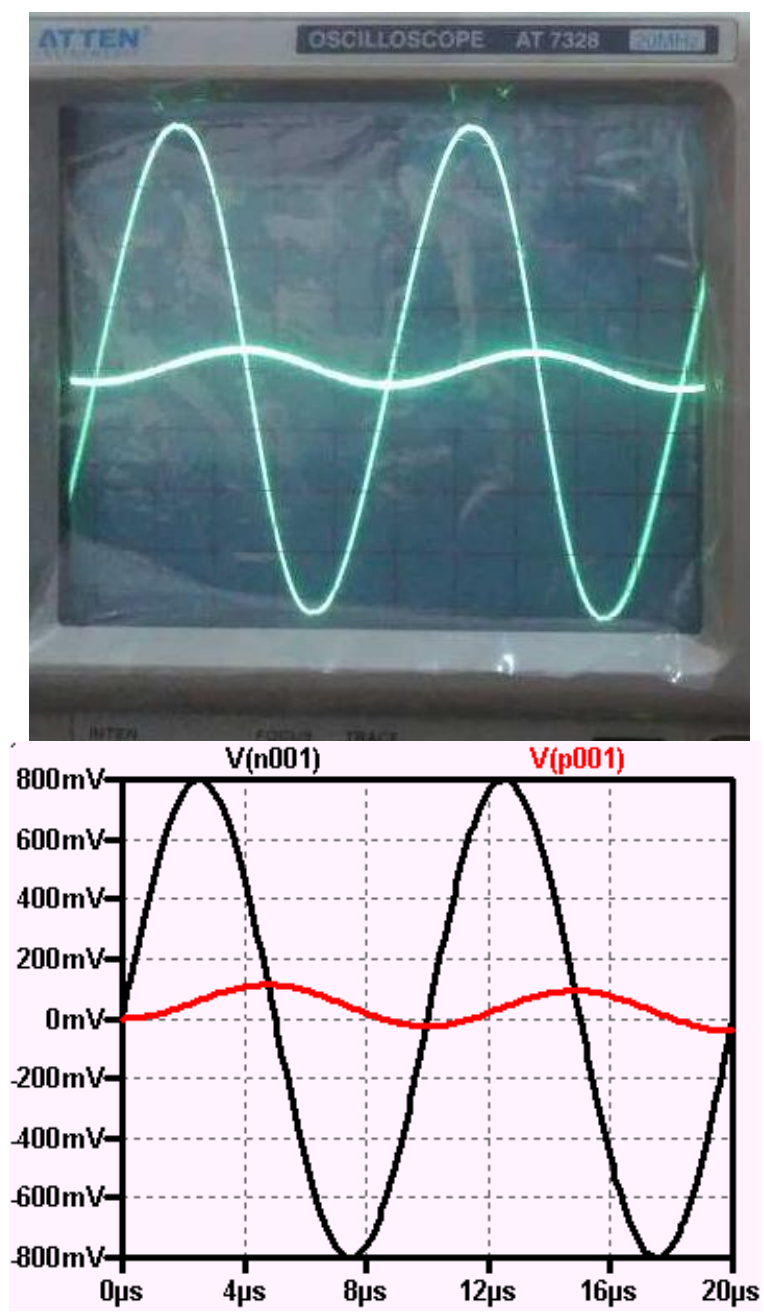

Gambar 12 Hasil eksperimen (kiri) dan simulasi (kanan) rangkaian bpf dengan $\mathrm{f}=100 \mathrm{kHz}$.
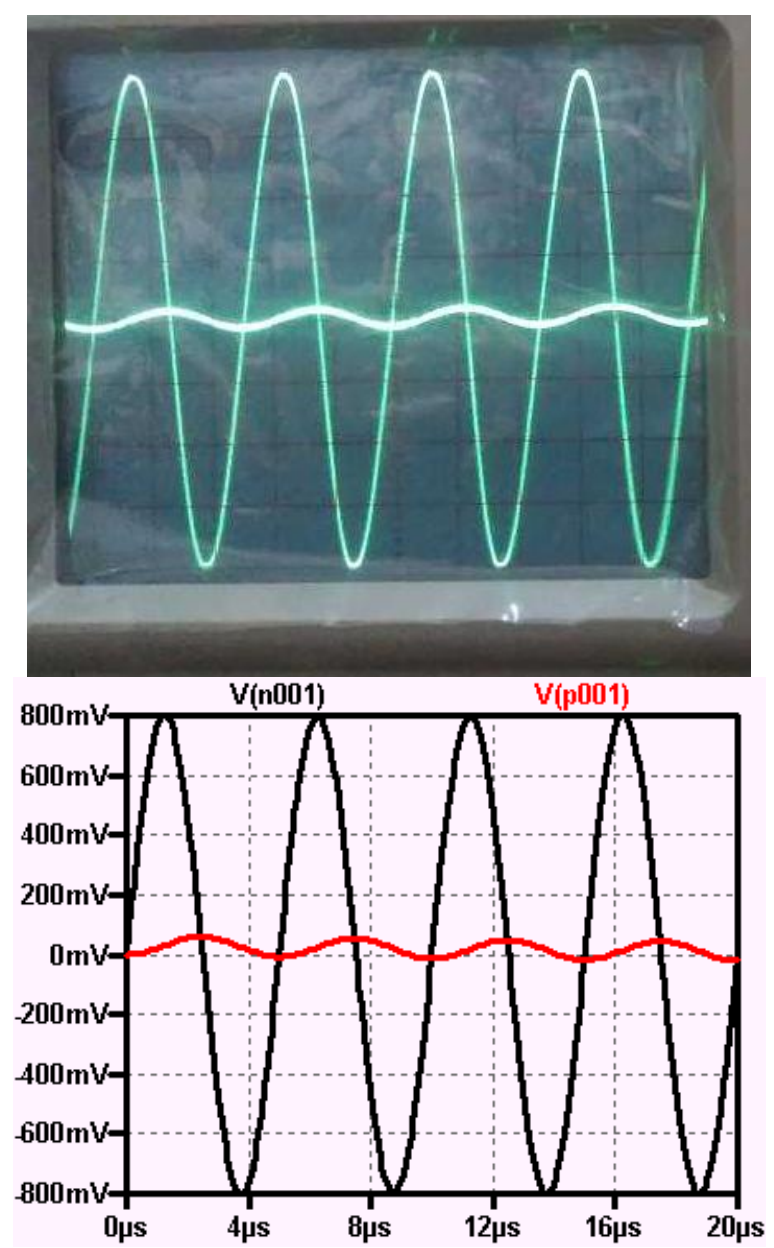

Gambar 13 Hasil eksperimen (kiri) dan simulasi (kanan) rangkaian bpf dengan $\mathrm{f}=200 \mathrm{kHz}$. 
RESISTOR (elektRonika kEndali telekomunikaSI tenaga liSTrik kOmputeR) Vol. 1 No. 2 e-ISSN : 2621-9700, p-ISSN : 2654-2684

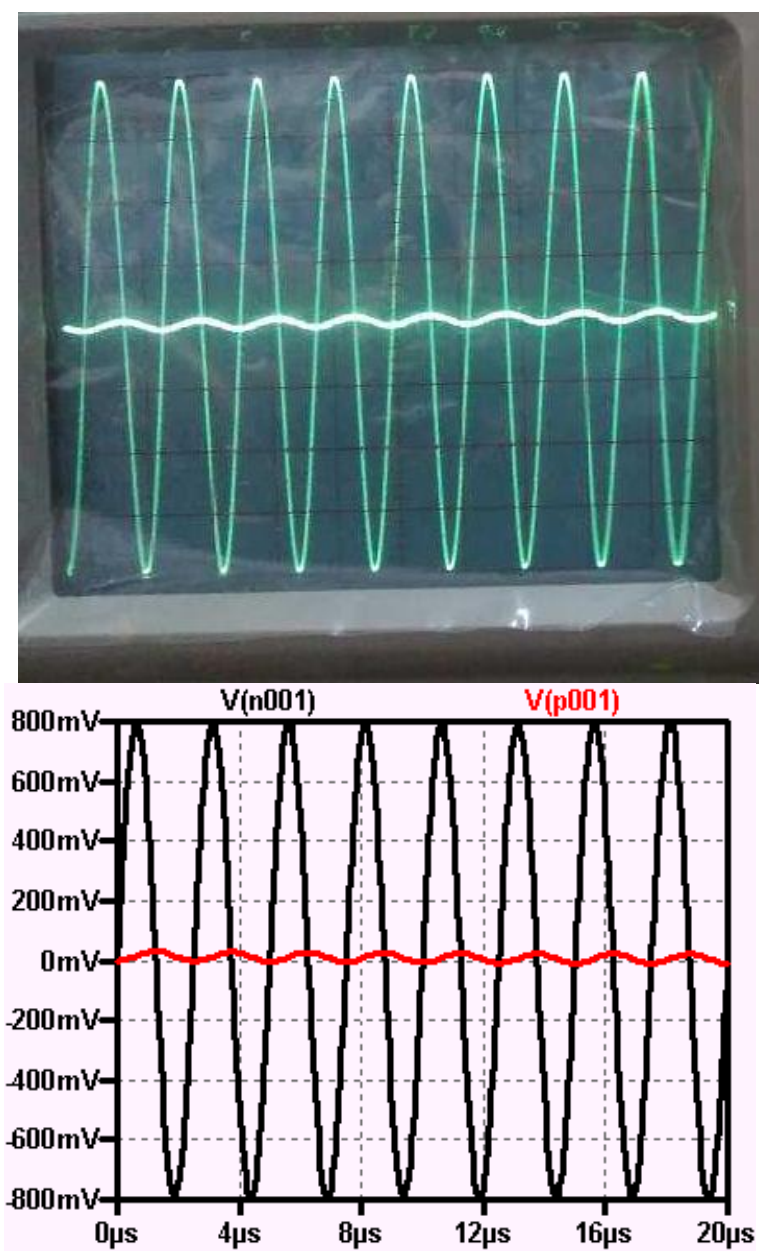

Gambar 14 Hasil eksperimen (kiri) dan simulasi (kanan) rangkaian bpf dengan $\mathrm{f}=400 \mathrm{kHz}$.
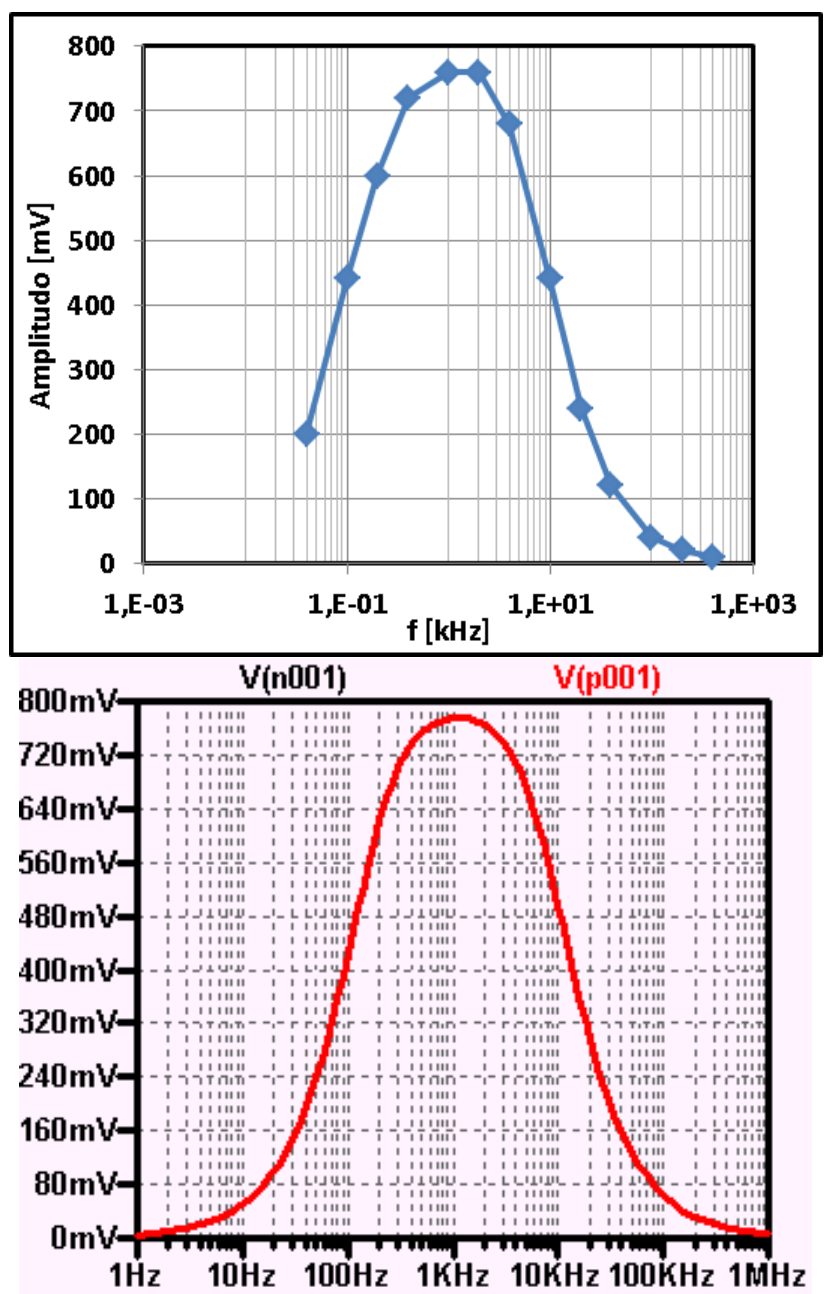

Gambar 15 Hasil eksperimen (kiri) dan simulasi (kanan) respon frekuensi rangkaian bpf

\section{KESIMPULAN}

Eksperimen dan simulasi terhadap rangkaian band pass filter telah dilakukan. Hasilnya menunjukkan bahwa pada rangkaian band pass filter yang telah disimulasikan dan dirangcang,ketika frekuensinya dinaikkan sampai $1 \mathrm{kHz}$, amplutidonya juga ikut naik, setelah itu, setelah frekuensinya iturunkan sampai $1 \mathrm{MHz}$, amplitudonya kembali turun.

\section{DAFTAR PUSTAKA}

[1] K. Ragupathi, J. I. Khan, M. Karthik, S. Rajan, and D. V. Kumar, "Design of Delay Lock Loop with Dual Control Using LT-Spice," International Journal of Scientific Research in Science, Engineering and Technology, vol. 1, no. 2, p. 5, 2015.

[2] Y. Wang, J. Chen, and C.-I. H. Chen, "Chebyshev Bandpass Filter Using Resonator of Tunable Active Capacitor and Inductor," VLSI Design, vol. 2017, pp. 1-12, 2017. 
RESISTOR (elektRonika kEndali telekomunikaSI tenaga liSTrik kOmputeR) Vol. 1 No. 2 e-ISSN : 2621-9700, p-ISSN : 2654-2684

[3] K.-H. Lee, E.-S. Kim, J.-G. Liang, and N.-Y. Kim, "Design and Realization of a Compact High-Frequency Band-Pass Filter with Low Insertion Loss Based on a Combination of a Circular-Shaped Spiral Inductor, Spiral Capacitor and Interdigital Capacitor," Electronics, vol. 7, no. 9, p. 195, Sep. 2018.

[4] S. W. Park and E. Sanchez-Sinencio, "RF Oscillator Based on a Passive RC Bandpass Filter," IEEE Journal of Solid-State Circuits, vol. 44, no. 11, pp. 3092-3101, Nov. 2009.

[5] M. N. Ibrahim, Z. H. C. Soh, I. H. Hamzah, and A. Othman, "A SIMULATION OF SINGLE STAGE BJT AMPLIFIER USING LTSPICE," e-Academia Journal UiTMT, vol. 5, no. 2, p. 8, 2016. 
RESISTOR (elektRonika kEndali telekomunikaSI tenaga liSTrik kOmputeR) Vol. 1 No. 2 e-ISSN : 2621-9700, p-ISSN : 2654-2684 